\title{
AVALIAÇÃO DISCENTE NA PERCEPÇÃO DE DOCENTES DA EDUCAÇÃO SUPERIOR
}

(1) VALESCA BRASIL IRALA'

(1) LIZIANE PADILHA MENA"

Iniversidade Federal do Pampa (Unipampa), campus Bagé, Bagé-RS, Brasil;
valescairala@unipampa.edu.br
" Universidade Federal do Pampa (Unipampa), campus Bagé, Bagé-RS, Brasil;
lizianemena1@gmail.com

\section{RESUMO}

Neste artigo, buscamos diagnosticar as formas de avaliação da aprendizagem, seus instrumentos e questões relacionadas e identificar possíveis indícios de inovações avaliativas emergentes em um campus de uma universidade pública do Sul do Brasil no âmbito de cursos de engenharias e licenciaturas na perspectiva de docentes. Assim, por meio da análise de planos de ensino semestrais e entrevistas com 11 docentes da instituição, com base na abordagem qualitativa, os resultados indicam que a prova ainda é descrita como o instrumento de maior peso entre os demais. Também, observamos a busca constante dos docentes por formas inovadoras de avaliar, concluindo que as mudanças são possíveis e necessárias no campo da avaliação discente, de forma que esta pesquisa mostra o início de um percurso de novas percepções.

PALAVRAS-chaVe AVALIAÇÃO DA EDUCAÇÃO • ENSINO SUPERIOR • INOVAÇÃO EDUCACIONAL • INSTRUMENTOS DE AVALIAÇÃO. 


\section{EVALUACIÓN ESTUDIANTIL EN LA PERCEPCIÓN DE DOCENTES DE LA EDUCACIÓN SUPERIOR}

\section{RESUMEN}

En este artículo intentamos diagnosticar las formas de evaluación del aprendizaje, los instrumentos y temas relacionados e identificar evidencias de innovaciones evaluativas emergentes en un campus de una universidad pública en el sur de Brasil, en el ámbito de cursos de ingeniería y de capacitación docente, desde la perspectiva de los formadores. De este modo, por medio del análisis de los planes de enseñanza semestrales y entrevistas con 11 docentes de la institución, en base a un enfoque cualitativo, los resultados indican que la prueba todavía se describe como el instrumento con mayor peso entre los demás. También se observó la constante búsqueda de los docentes por formas innovadoras de evaluar, lo que permite concluir que los cambios son posibles y necesarios en el ámbito de la evaluación estudiantil, de modo que esta investigación muestra el inicio de un itinerario de nuevas percepciones.

PALABRAS CLAVE EVALUACIÓN EN LA EDUCACIÓN • ENSEÑANZA SUPERIOR • INNOVACIÓN EDUCACIONAL・INSTRUMENTOS DE EVALUACIÓN.

\section{STUDENT ASSESSMENT IN THE PERCEPTION OF HIGHER EDUCATION PROFESSORS}

\section{ABSTRACT}

In this article, we seek to diagnose forms of learning assessment, the instruments and related issues, and to identify possible indications of emerging evaluative innovations on a campus of a public university in southern Brazil, in some undergraduate engineering and teacher education programs, from the perspective of the professors. Thus, from the analysis of the college syllabi and interviews with 11 professors of the institution, using a qualitative approach, the results indicate that the test is still described as the tool with greater weight among the others. We also observed the constant search by professors for innovative ways to assess, concluding that changes are possible and necessary in the field of student assessment, such that this study shows the beginning of a path of new perceptions.

KEYWORDS HIGHER EDUCATION • ASSESSMENT FORT LEARNING • EDUCATIONAL INNOVATION • ASSESSMENT INSTRUMENTS. 


\section{INTRODUÇÃO}

Esta pesquisa se desenvolveu no âmbito de um projeto intitulado "Materiais didáticos autorais e avaliação no ensino: políticas educacionais situadas”, vinculado ao Grupo de Pesquisa sobre Aprendizagens, Metodologias e Avaliação (Gama), e parte de discussões acerca da avaliação da aprendizagem no ensino superior, tomando por base concepções e práticas relatadas por docentes de cursos de engenharias e licenciaturas de uma universidade pública multicampi, localizada na fronteira do Rio Grande do Sul com o Uruguai e a Argentina, a qual se caracteriza por estar inserida em um contexto socioacadêmico desfavorável (ACEVEDO, 2018), a partir de uma perspectiva histórico-sociológica mais ampla de estagnação estrutural da região.

Entendemos que a escuta e a discussão da prática de avaliação nesse contexto possam contribuir para reflexões e consequentes melhorias, não apenas dos docentes sujeitos desta pesquisa, mas também de docentes que se identifiquem com as situações relatadas. Consideramos que a observação do perfil profissional que se pretende formar e o projeto político-pedagógico da instituição de ensino superior (IES), articulados aos objetivos, conteúdos e métodos pedagógicos, são pilares para definir e compreender a função da avaliação no processo de ensino e de aprendizagem (CHAVES, 2004).

Dessa forma, ancoramo-nos nas percepções de Luckesi (2011), entendendo a avaliação por meio de uma tomada de posição sobre o sujeito avaliado para aceitá-lo ou transformá-lo, baseando-se em um ajuizamento de qualidade das tarefas por ele executadas. Além disso, o mesmo autor ressalta que a função da avaliação se pauta no diagnóstico de uma dada situação em busca de constantes avanços nos desempenhos discentes, não apenas em uma dimensão intelectual, mas também atitudinal e relacional, ou seja, compreendendo aspectos mais amplos do que aqueles que tradicionalmente são avaliados, inserindo-se no campo de uma avaliação socioformativa (TOBÓN, 2017).

Partindo disso, baseamo-nos na tradição das concepções de avaliações classificatórias e formativas, sendo as primeiras pautadas na centralidade da memorização, e as segundas, no acompanhamento do processo de construção dos conhecimentos práticos e científicos desenvolvidos ao longo da formação universitária (HOFFMANN, 2001; DOCHY; SEGERS; DIERICK, 2002; LUCKESI, 2011; FRAILE et al., 2020). Ressaltamos, entretanto, a necessidade de problematizar, para além dos extremos, com a necessidade de intersecções e a fundamentação de uma perspectiva que norteia a busca pela qualidade das experiências dos estudantes em relação ao conhecimento, compreendendo experiência como aquilo que nos toca, que nos acontece e que nos modifica (BONDÍA, 2002).

Nesse contexto, tivemos como objetivos: (a) diagnosticar as formas de avaliação da aprendizagem, seus instrumentos e questões relacionadas; e (b) identificar 
possíveis indícios de inovações avaliativas emergentes em um campus de uma universidade pública multicampi localizada no Sul do Brasil no âmbito de cursos de engenharias e de licenciaturas na perspectiva de docentes atuantes nessa IES. A inovação aqui é entendida em uma perspectiva situada e ancorada nas discussões internacionais acerca da inovação avaliativa (NORAINIIDRIS et al., 2015; FLUCK; HILLIER, 2016; LOCK et al., 2018; VON DAVIER; ZHU; KYLLONEN, 2017).

Assim como Blass, Goergen e Irala (2020, p. 1569), entendemos que uma perspectiva situada aponta para a "[...] tomada de decisões locais, pautadas nas demandas e problemáticas nascidas em um cenário específico e orientadas à construção de respostas criativas, críticas e embasadas teoricamente", porém “[...] coerentes e adaptáveis ao contexto de ensino a que se vinculam". Ou seja, assumimos um olhar sensível para compreender que o processo de mudança no campo avaliativo não é independente de seus agentes (áreas de formação, visões teóricas, crenças etc.) e que em um mesmo cenário institucional podem coabitar diferentes concepções e práticas sobre o que se pode conceber como avaliação inovadora.

Nossa intenção não é, nem poderia ser, esgotar a discussão, mas sim contribuir para explicitá-la, partindo do argumento basal de que as reflexões acerca da avaliação no ensino superior são enriquecidas e aprofundadas à medida que se debatem e se investigam como fazer, por que fazer e quais são os impactos dos procedimentos adotados no desempenho e sucesso acadêmico dos estudantes, com vistas a garantir a sua permanência no ensino superior (TINTO, 2012).

Na próxima seção, traremos brevemente uma discussão sobre os caminhos da avaliação da aprendizagem, para, na sequência, dar suporte aos procedimentos metodológicos e analíticos próprios dos objetos analisados nesta pesquisa.

\section{CAMINHOS DA AVALIAÇÃO DA APRENDIZAGEM}

A avaliação educacional adotada no Brasil hoje, em moldes tradicionalmente conhecidos, sofreu grande influência do modelo norte-americano, forjado desde o início do século XX, dada a forte presença das agências financiadoras externas nos programas educacionais brasileiros, passando a ganhar contornos mais expressivos nas últimas décadas (VIANNA, 2014a). De forma mais específica, mais recentes são os contornos em relação a uma mudança da cultura da "prova" (testing) para a cultura da "avaliação" (assessment) no contexto do ensino superior (DOCHY; SEGERS; DIERICK, 2002; CARLESS, 2009), voltados para se pensar o desempenho discente em diálogo com processos mais amplos do contexto de ensino-aprendizagem (DEPRESBITERIS; TAVARES, 2017; VIANNA, 2014b). Coincidimos em nossas reflexões com a crítica apontada e a consideramos, infelizmente, ainda atual: 
A avaliação em nosso contexto educacional acha-se na fase da pré-história, preocupada com problemas menores e sem significado efetivo para o sucesso de uma aprendizagem realmente consequente para o ser humano diante dos desafios que a sociedade constantemente apresenta. (VIANNA, 2014b, p. 175)

Por outro lado, movimentos de mudança nas perspectivas da educação têm refletido na forma como a avaliação vem sendo entendida, com a defesa na diversificação de instrumentos e técnicas, a ênfase na busca da qualidade, a superação da ideia de avaliação como um julgamento final, a introdução dos conceitos de "avaliação formativa" e "somativa" (CARLESS, 2009; FRAILE et al., 2020), o estreitamento entre a avaliação de microestruturas (em sala de aula e na perspectiva curricular), mesoestruturas (as instituições) e macroestruturas (avaliação nacional e internacional), a avaliação orientada à tomada de decisão, maior conscientização em relação às questões éticas atreladas à avaliação, o papel da metacognição, a discussão dos dados de avaliação como uma parte primordial de todo o processo, entre outros (DEPRESBITERIS; TAVARES, 2017; HADJI, 2001; HOFFMANN, 2001; LUCKESI, 2011).

No âmbito do ensino superior, de forma geral, a cultura da "prova" (DOCHY; SEGERS; DIERICK, 2002) como sinônimo de avaliação parece ser ainda muito presente, especialmente em algumas áreas do conhecimento mais tradicionais. Entretanto, outras perspectivas são cada vez mais imperativas, acompanhando as indicações teóricas, uma vez que diversos estudos vêm sinalizando a importância de repensar as formas de avaliar, por meio da frutífera discussão do campo das inovações avaliativas no ensino superior em diversos contextos e países (NORAINIIDRIS et al., 2015; FLUCK; HILLIER, 2016; LOCK et al., 2018; VON DAVIER; ZHU; KYLLONEN, 2017).

Os instrumentos de avaliação têm papel intermediador nesse caminho e, uma vez entendidos como "[...] todas as formas de expressão do aluno que permitam acompanhar seu processo de aprendizagem” (HOFFMANN, 2001, p. 178), possibilitam a observação do crescimento individual, porém em um contexto coletivo. Além disso, os instrumentos, com a função de orientar o professor no decorrer do processo de ensino, bem como o estudante em relação às próprias aprendizagens, podem ser definidos como os "procedimentos didáticos" usados para observar aspectos fundamentais da aprendizagem dos estudantes (GONÇALVES; LARCHERT, 2011).

Feita essa breve contextualização da problemática relacionada às mudanças em curso no cenário avaliativo das instituições de ensino, de forma geral, defendemos o crescente estreitamento entre a pesquisa "sobre" e a prática avaliativa em si, superando, assim, visões apenas intuitivas ou supostamente "técnicas" do ato de avaliar, em direção a um caminho permeado por orientações teóricas que se retroalimentam de experiências avaliativas situadas (BLASS; IRALA, 2020) e reflexivas, as quais buscam a superação das dificuldades reais que perpassam todo o processo 
avaliativo. Na próxima seção, traremos os percursos metodológicos empreendidos para a análise dos dados utilizados na construção deste texto.

\section{PERCURSOS METODOLÓGICOS}

Partimos inicialmente da pesquisa documental (CECHINEL et al., 2016) dos planos de ensino de todos os componentes curriculares ofertados em um campus universitário, os quais diziam respeito a 11 cursos de graduação, entre os quais seis licenciaturas e cinco bacharelados em Engenharia oferecidos naquele campus.

Após serem identificados quais docentes apresentavam na metodologia dos seus planos de ensino uma maior diversificação dos instrumentos avaliativos, bem como maior detalhamento de suas práticas avaliativas no que diz respeito também à recuperação da aprendizagem (item obrigatório do plano de ensino), selecionamos 11 professores (com a representação de pelo menos um docente por curso) para participar de uma entrevista estruturada, pautada em um roteiro com dez questões abertas sobre suas práticas de avaliação. Assim, este estudo, de abordagem qualitativa (BOGDAN; BIKLEN, 1994), é pautado na triangulação de dados obtidos através dos planos de ensino dos professores selecionados e nas entrevistas realizadas, com respaldo no referencial teórico. Tais docentes foram considerados, na perspectiva por nós adotada, como potenciais vetores de inovação avaliativa, entendida por nós sempre de forma localmente situada (DORNELLES, 2012).

As entrevistas foram escolhidas como instrumento de produção de dados por apresentarem maior flexibilidade em relação a outros instrumentos, como questionário ou formulários, por exemplo, uma vez que possibilitam maior liberdade de expressão por parte do entrevistado e, dessa forma, maior riqueza dos dados produzidos. As entrevistas estruturadas são entendidas como aquelas em que o entrevistador possui um roteiro bem definido, que sustenta a produção dos dados (MASSONI; MOREIRA, 2016).

Boni e Quaresma (2005) definem as entrevistas estruturadas como aquelas que são formuladas a partir de um questionário com perguntas previamente elaboradas e buscando não fugir desse roteiro durante o curso da entrevista. Para Britto Júnior e Feres Júnior (2011), esse tipo de entrevista ocorre com base em uma relação fixa de questões que, em geral, são invariáveis para os entrevistados.

As entrevistas foram gravadas em áudio, transcritas e analisadas em uma perspectiva qualitativa, entendida por Silveira e Córdova (2009, p. 31) como aquela cujo eixo central é a compreensão “[...] de um grupo social, de uma organização, etc.”. Primando pelos princípios éticos, os professores foram identificados no decorrer do texto com os pseudônimos: Frederico, Eduardo, Márcia, Helen, Fabiola, Denise, Sueli, Paulo, Lúcio, Gustavo e Gisele. 
As gravações em áudio das entrevistas realizadas foram transcritas mantendo a maior similitude possível com as características da oralidade (por exemplo, usou-se :: para simular o alongamento das vogais). Dados produzidos foram triangulados com dados provenientes da análise dos planos de ensino e com o referencial teórico. A triangulação de dados pode ser definida como a combinação de dados extraídos de diferentes fontes e em diferentes momentos, em locais ou de pessoas diferentes. Dessa forma, a triangulação pode ser realizada entre pelo menos duas ou mais perspectivas privilegiadas do tema estudado (BORTONI-RICARDO, 2008; FLICK, 2013). Na próxima seção, apresentamos a análise dos resultados.

\section{CONFIGURAÇÃO DOS RESULTADOS}

Os resultados iniciais, apresentados no Quadro 1, têm por finalidade situar o leitor em relação aos cursos e componentes curriculares pesquisados, relacionando-os aos respectivos docentes. O critério demarcado para a escolha dos docentes entrevistados se deu a partir da análise de todos os planos de ensino, de todos os componentes dos cursos do campus universitário investigado, buscando identificar qual componente, entre os ofertados no segundo semestre de 2017, em cada curso, apresentava maior diversificação de instrumentos avaliativos.

\section{QUADRO 1 - Cursos e componentes curriculares}

\begin{tabular}{|c|c|c|}
\hline PROFESSOR & CURSO & COMPONENTE CURRICULAR \\
\hline Frederico & Engenharia de Energia & Resistência dos Materiais \\
\hline Eduardo & Engenharia Química & Química Geral I \\
\hline Márcia & Licenciatura em Química & Práticas Vocais Coletivas IV \\
\hline Helen & Licenciatura em Música & Multiletramentos \\
\hline Fabiola & Letras - Português & Prática de Ensino de Língua Portuguesa e Literatura \\
\hline Denise & Letras - Línguas Adicionais (Inglês e & \\
\hline Sueli & Espanhol) & Laboratório para o Ensino Fundamental \\
\hline Paulo & Licenciatura em Matemática & Laboratório de Física III \\
\hline Lúcio & Engenharia de Produção & Laboratório de Química Geral \\
\hline Gustavo & Licenciatura em Física & Física Geral III \\
\hline Gisele & Engenharia de Alimentos & Economia Industrial \\
\hline
\end{tabular}

Fonte: Elaboração das autoras (2020).

Percebeu-se que cinco professores lecionavam, à época da coleta dos dados, em cursos de bacharelado, todos em Engenharia, mas com especialidades diferentes, entre as quais: Engenharia Química, de Alimentos, de Energia, de Produção e de 
Computação. Além disso, notou-se que os componentes analisados e aos quais foram direcionadas as entrevistas, pelo critério de apresentar maior variabilidade de instrumentos de avaliação, são dispostos na matriz curricular entre o terceiro e quinto semestre de cada curso e são ofertados em caráter obrigatório.

Esse é um achado relevante, uma vez que os alunos passam a ter contato com maior variedade de instrumentos de avaliação a partir da segunda metade dos cursos. Com isso, percebe-se uma lacuna no campo avaliativo existente na primeira metade dos cursos, momento em que poderiam começar a desenvolver habilidades próprias da área de atuação profissional a que se destinam e, possivelmente, contribuir assim para amenizar os índices de evasão discente, concentrados predominantemente nos semestres iniciais dos respectivos cursos, no caso da IES analisada e em outras mencionadas na literatura (CAMARGO et al., 2014; MISSIO et al., 2016; ZIMMERMANN et al., 2011).

\begin{abstract}
É preciso, portanto, retomar o princípio fundamental da expressão do conhecimento: o que ouvimos, vemos ou lemos não é o pensamento do aluno, mas sua expressão, que também evolui, se aprimora, precisa ser trabalhada [...]. Aprendemos e sentimos muito mais e de jeito diferente do que expressamos. Assim, é preciso analisar as manifestações dos alunos absorvendo as duas dimensões: a interpretação de seus entendimentos e da forma de expressão de tais entendimentos. (HOFFMANN, 2001, p. 165)
\end{abstract}

No mesmo sentido, Luckesi (2011, p. 263) afirma que "[...] a eficiência na aprendizagem não depende só do aprendiz, mas, ao mesmo tempo, do ensinante e do sistema”. Nesse contexto, a avaliação constitui a comunicação entre quais objetivos o aluno efetivamente alcançou e, também, aspectos relacionados à prática do professor. Outro fator importante é a configuração dos componentes curriculares em que, no caso dos bacharelados, entre os cinco componentes analisados, quatro apresentam carga horária prática, como se observa no Quadro 2.

\title{
QUADRO 2 - Distribuição das cargas horárias dos bacharelados
}

\begin{tabular}{|c|c|c|c|}
\hline COMPONENTE & C. H. TOTAL & C. H. PRÁTICA & C. H. TEÓRICA \\
\hline Resistência dos Materiais & $60 \mathrm{~h}$ & $15 \mathrm{~h}$ & $45 \mathrm{~h}$ \\
\hline Química Orgânica Experimental I & $60 \mathrm{~h}$ & $60 \mathrm{~h}$ \\
\hline Laboratório de Química III & $30 \mathrm{~h}$ & $30 \mathrm{~h}$ & $0 \mathrm{~h}$ \\
\hline Laboratório de Química Geral & $30 \mathrm{~h}$ & $30 \mathrm{~h}$ & $0 \mathrm{~h}$ \\
\hline Economia Industrial & $30 \mathrm{~h}$ & $0 \mathrm{~h}$ & $30 \mathrm{~h}$ \\
\hline
\end{tabular}

Fonte: Elaboração das autoras (2020). 
Dessa forma, a variabilidade de instrumentos nesses componentes pode ser justificada pelo caráter prático que lhes é inerente, que, em geral, estimula de forma mais explícita a utilização de instrumentos diversos, voltados a avaliar, geralmente, aspectos próprios da prática laboratorial.

Já entre as seis licenciaturas, em Física, Música, Química, Matemática, Letras Português e Letras - Línguas Adicionais (Inglês e Espanhol), dos seis componentes, ministrados entre o primeiro e o quarto semestres dos cursos, quatro apresentaram carga horária prática, como se observa no Quadro 3.

\section{QUADRO 3 - Distribuição das cargas horárias das licenciaturas}

\begin{tabular}{|c|c|c|c|c|}
\hline COMPONENTE & C. H. TOTAL & C. H. PRÁTICA & C. H. TEÓRICA & C. H. SEMIPRESENCIAL \\
\hline Química Geral I & $90 \mathrm{~h}$ & $30 \mathrm{~h}$ & $60 \mathrm{~h}$ & $0 \mathrm{~h}$ \\
\hline Práticas Vocais Coletivas IV & $45 \mathrm{~h}$ & $45 \mathrm{~h}$ & $0 \mathrm{~h}$ & $0 \mathrm{~h}$ \\
\hline $\begin{array}{c}\text { Prática de Ensino de Língua } \\
\text { Portuguesa e Literatura }\end{array}$ & $90 \mathrm{~h}$ & $60 \mathrm{~h}$ & $0 \mathrm{~h}$ & $0 \mathrm{~h}$ \\
\hline Multiletramentos & $75 \mathrm{~h}$ & $0 \mathrm{~h}$ & $75 \mathrm{~h}$ & $0 \mathrm{~h}$ \\
\hline $\begin{array}{c}\text { Laboratório para o Ensino } \\
\text { Fundamental }\end{array}$ & $60 \mathrm{~h}$ & $30 \mathrm{~h}$ & $30 \mathrm{~h}$ & $0 \mathrm{~h}$ \\
\hline Física Geral III & $90 \mathrm{~h}$ & $0 \mathrm{~h}$ & $90 \mathrm{~h}$ & 0 \\
\hline
\end{tabular}

Fonte: Elaboração das autoras (2020).

Nos cursos de licenciatura também ocorre a predominância da carga horária prática nos componentes com maior diversificação de instrumentos de avaliação; entretanto, ela diz respeito tanto às práticas de laboratório quanto às práticas de canto e de atividades de microensino em escolas; logo, os instrumentos e formas de avaliação são adaptados a essas necessidades. Além disso, entre os componentes analisados, apenas o de Práticas Vocais Coletivas IV era de caráter eletivo.

Considerando a carga horária prática como eixo importante para a formação profissional, tanto de bacharéis quanto de futuros docentes, ressalta-se a definição do Parecer CNE/CP n. 28/2001 em relação às práticas em cursos superiores:

\footnotetext{
Não resta dúvida que estes pontos não devem e não podem ser entendidos como atividades estanques ou como blocos mecânicos separados entre si. Estes pontos devem e podem formar um todo em que todas as atividades teórico-práticas devem ser articuladas em torno de um projeto pedagógico elaborado de modo orgânico e consistente. (BRASIL, 2001)
}

Nos planos de ensino, perceberam-se semelhanças entre os formatos de avaliação e de recuperação da aprendizagem descritas, especialmente entre os componentes de laboratório. Os instrumentos de avaliação e características da recuperação são descritos no Quadro 4. 


\section{QUADRO 4 - Descrição da avaliação e recuperação nos planos de ensino dos entrevistados ${ }^{1}$}

\begin{tabular}{|c|c|c|}
\hline COMPONENTE & AVALIAÇÃO & RECUPERAÇÃO \\
\hline $\begin{array}{l}\text { Resistência dos } \\
\text { Materiais }\end{array}$ & Duas provas teóricas e um trabalho teórico-prático. & $\begin{array}{c}\text { Avaliação substitutiva da avaliação de } \\
\text { menor nota. Atividades preventivas da } \\
\text { monitoria. }\end{array}$ \\
\hline $\begin{array}{l}\text { Química Orgânica } \\
\text { Experimental I }\end{array}$ & $\begin{array}{l}\text { Relatório cumulativo semestral, caderno de } \\
\text { laboratório, prova teórica e prova prática. }\end{array}$ & $\begin{array}{c}\text { Atividades não presenciais. Para notas } \\
\text { abaixo de 6,0: prova substitutiva da nota } \\
\text { da(s) prova(s) abaixo do rendimento de } \\
60 \% .\end{array}$ \\
\hline Química Geral I & $\begin{array}{c}\text { Relatório, caderno de laboratório, duas provas } \\
\text { teórico-práticas, comportamento. }\end{array}$ & $\begin{array}{l}\text { Atividades não presenciais. Prova } \\
\text { referente ao conteúdo da prova em que o } \\
\text { aluno não logrou aprovação. }\end{array}$ \\
\hline $\begin{array}{l}\text { Práticas Vocais } \\
\text { Coletivas IV }\end{array}$ & $\begin{array}{l}\text { Avaliação diagnóstica individual: exercícios de técnica } \\
\text { vocal e domínio de sua linha vocal. Avaliação coletiva: } \\
\text { domínio vocal dos arranjos cantados e domínio do } \\
\text { repertório proposto para o semestre. }\end{array}$ & Atendimentos individuais. \\
\hline $\begin{array}{l}\text { Prática de } \\
\text { Ensino de Língua } \\
\text { Portuguesa e } \\
\text { Literatura }\end{array}$ & $\begin{array}{l}\text { Seminários, diários reflexivos sobre as atividades } \\
\text { de observação do contexto escolar, apresentação } \\
\text { na atividade de microensino, sequência didática } \\
\text { da atividade de microensino, comprometimento e } \\
\text { autoavaliação, leitura dos textos, participação. }\end{array}$ & $\begin{array}{c}\text { Ao longo do semestre, com a retomada } \\
\text { dos textos e materiais produzidos, } \\
\text { sua revisão e reformulação com } \\
\text { entrega programada para a semana } \\
\text { imediatamente posterior à do prazo } \\
\text { estipulado. }\end{array}$ \\
\hline Multiletramentos & $\begin{array}{c}\text { Engagement, Tasks, apresentação oral, produções } \\
\text { criativas. }\end{array}$ & $\begin{array}{l}\text { Realização de novas produções. Não há } \\
\text { atividade final de recuperação. }\end{array}$ \\
\hline $\begin{array}{l}\text { Laboratório } \\
\text { para o Ensino } \\
\text { Fundamental }\end{array}$ & $\begin{array}{c}\text { Frequência e participação em atividades em aulas } \\
\text { presenciais no LEF, participação na elaboração das } \\
\text { ideias e concretização dos materiais manipuláveis } \\
\text { para as atividades no LEF, elaboração de material } \\
\text { ou atividade com o uso de tecnologias, avaliação } \\
\text { individual (prova envolvendo conteúdos explorados } \\
\text { ao longo do componente, elaboração de portfólios } \\
\text { ou laboratórios digitais, fichas de atividades, entre } \\
\text { outros). Participações em ações interdisciplinares e } \\
\text { voluntárias. }\end{array}$ & $\begin{array}{c}\text { Orientações individuais e/ou coletivas, } \\
\text { a fim de recuperar e aprimorar as } \\
\text { práticas de elaboração de atividades de } \\
\text { LEF, envolvendo leituras e discussões } \\
\text { teóricas. }\end{array}$ \\
\hline $\begin{array}{l}\text { Laboratório de } \\
\text { Física III }\end{array}$ & $\begin{array}{l}\text { Avaliação escrita individual, relatórios. A média } \\
\text { aritmética entre os dois módulos determina o } \\
\text { terceiro. Se } M \geq 6 \text {, o aluno trabalhará com materiais } \\
\text { complementares e apresentará um trabalho final. Se } \\
M<6 \text {, o aluno fará trabalhos de recuperação. }\end{array}$ & $\begin{array}{l}\text { Listas de exercícios e refazendo } \\
\text { experimentos de acordo com as } \\
\text { deficiências detectadas pelas duas } \\
\text { primeiras avaliações (A1 e A2). }\end{array}$ \\
\hline $\begin{array}{l}\text { Laboratório de } \\
\text { Química Geral }\end{array}$ & $\begin{array}{l}\text { Relatórios, caderno de laboratório das atividades } \\
\text { práticas realizadas, participação, desempenho e } \\
\text { presença em aula, duas provas. }\end{array}$ & $\begin{array}{l}\text { Ao longo do semestre, com leituras } \\
\text { dirigidas, trabalhos individuais e dirigidos. }\end{array}$ \\
\hline Física Geral III & $\begin{array}{l}\text { Uma avaliação ao término de cada capítulo do livro } \\
\text { texto. }\end{array}$ & $\begin{array}{l}\text { Não há avaliação substitutiva com todo o } \\
\text { conteúdo. As eventuais deficiências são } \\
\text { discutidas nos momentos oportunos. }\end{array}$ \\
\hline $\begin{array}{l}\text { Economia } \\
\text { Industrial }\end{array}$ & Duas provas um seminário e estudos dirigidos. & $\begin{array}{l}\text { Observação das atividades práticas } \\
\text { realizadas no componente curricular. } \\
\text { Prova de substituição com todo o } \\
\text { conteúdo. }\end{array}$ \\
\hline
\end{tabular}

Fonte: Elaboração das autoras (2020).

Com base nos instrumentos citados nos planos de ensino, realizou-se a análise agrupando instrumentos de acordo com o esquema apresentado na Figura 1,

1 Os dados que constituem o Quadro 4 são recortes diretos dos planos de ensino analisados, sem interferência das pesquisadoras na redação, a fim de manter a fidelidade aos dados na análise e situar o leitor. 
considerando a quantidade de planos de ensino em que os referidos instrumentos foram citados.

\section{FIGURA 1 - Agrupamento dos instrumentos citados nos planos de ensino}

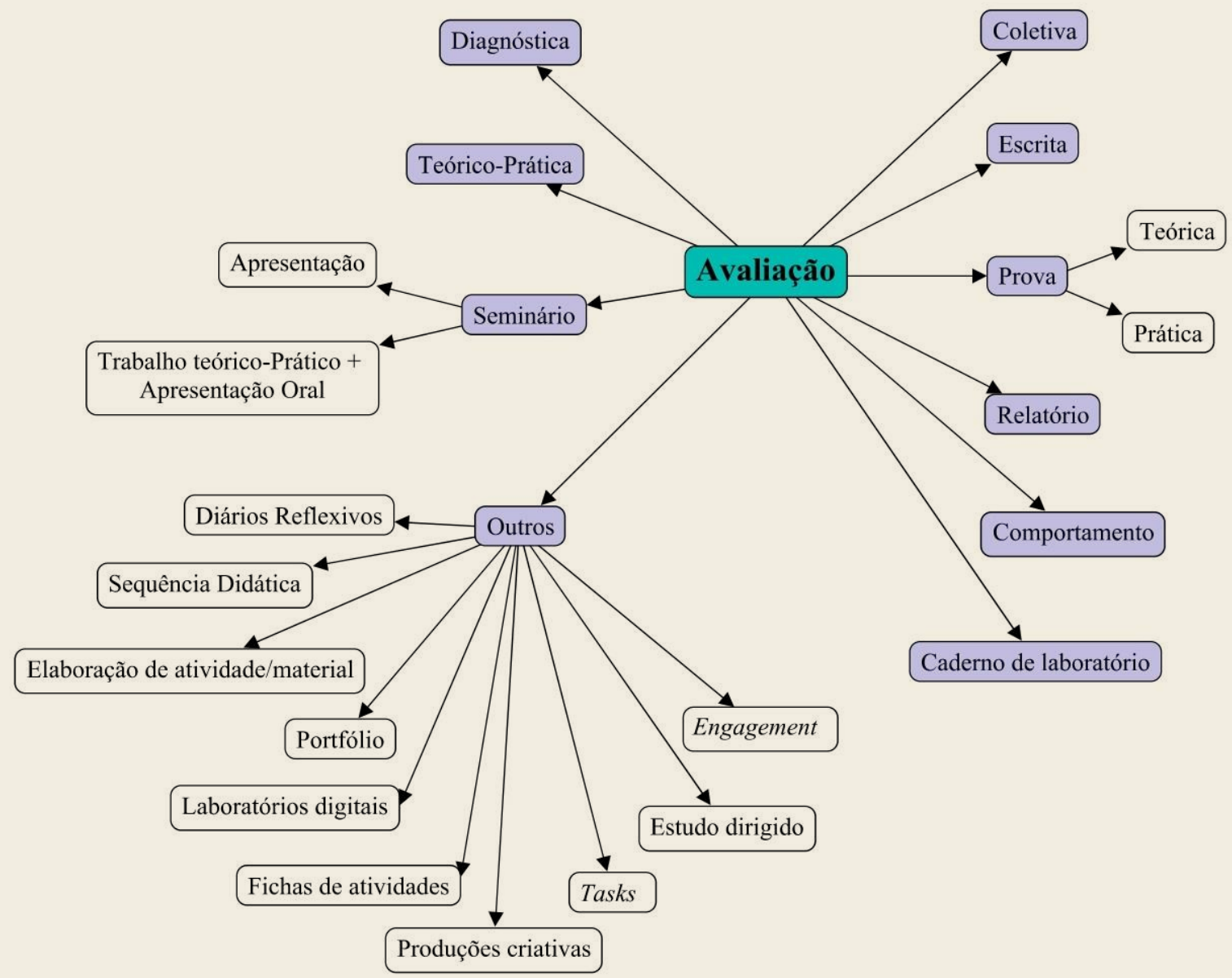

Fonte: Elaboração das autoras (2020).

A partir da análise desses grupos, percebeu-se a predominância de seis instrumentos de avaliação, entre os quais se sobressai a prova, seguida por avaliações escritas (coletivas ou diagnósticas), relatórios, seminários e cadernos de laboratório. Também constam questões como comportamento, frequência e participação durante as aulas, embora não sejam especificados nos planos os critérios para avaliar tais dimensões. Instrumentos citados em apenas um plano de ensino foram enquadrados em "outros".

Em relação à prova, instrumento mais citado nos planos de ensino analisados, consideramos que pode, sim, ser utilizada a favor da perspectiva formativa de avaliação, desde que a formulação das questões siga os aspectos trabalhados durante as aulas, com critérios de correção definidos, compartilhados e discutidos com os alunos, bem como inserida em um contexto que permita observar as demais dimensões da aprendizagem e realizar ações para que as inadequações sejam ressignificadas 
(DEPRESBITERIS; TAVARES, 2017; HOFFMANN, 2001; LUCKESI, 2011). As avaliações descritas nos planos de ensino como diagnóstica, escrita e coletiva são direcionadas a conhecer a turma, os aspectos individuais dos alunos, seus conhecimentos prévios a respeito do componente curricular.

Em relação à recuperação, a Lei de Diretrizes e Bases da Educação Nacional (LDBEN) n. 9.394 (BRASIL, 1996) prevê a “[...] obrigatoriedade de estudos de recuperação, de preferência paralelos ao período letivo, para os casos de baixo rendimento escolar, a serem disciplinados pelas instituições de ensino em seus regimentos". Hadji (2001) destaca as atividades de recuperação com função remediadora e voltada ao passado, uma vez que costumam incluir a repetição de atividades e lições e resolução de exercícios do mesmo tipo. O autor reflete que dever-se-ia pensar, a partir de tais atividades, em novas atividades e contextos, permitindo o ajuste das ações do professor, bem como melhor expressão dos alunos.

Entretanto, os dados analisados permitem observar que a recuperação paralela, ao longo do semestre letivo, nem sempre é realizada, ocorrendo avaliações de substituição de notas ou trabalhos para esse fim em alguns casos, como se observou no Quadro 4. Em função da recuperação, ressalta-se a função do erro como fonte a ser explorada pelo professor, uma vez que "[...] uma visão sadia do erro possibilita sua utilização de forma sadia” (LUCKESI, 2011, p. 189). Desse modo, seria possível a realização de uma recuperação paralela ao processo de aprendizagem e focada em soluções para as dificuldades individuais, o que requer também uma mudança na crença dos estudantes, que também se mobilizam frente à ideia de uma recuperação apenas realizada ao fim do semestre letivo, sem uma compreensão clara do papel da recuperação paralela, de forma geral.

Nas entrevistas, os professores citam ainda mais instrumentos do que aqueles apresentados nos planos de ensino; entretanto, a prova escrita também foi citada como principal recurso de avaliação, como se observa no Quadro 5. 
QUADRO 5 - Instrumentos descritos nas entrevistas

\begin{tabular}{|c|c|c|}
\hline PROFESSOR & COMPONENTE CURRICULAR & INSTRUMENTOS \\
\hline Frederico & Resistência dos Materiais & Prova e trabalho teórico-prático \\
\hline Eduardo & Química Orgânica Experimental I & $\begin{array}{l}\text { Prova (teórica e prática), relatório de aula } \\
\text { experimental, caderno de laboratório }\end{array}$ \\
\hline Márcia & Química Geral I & $\begin{array}{l}\text { Seminários, trabalhos teóricos, relatório, } \\
\text { caderno de laboratório, prova }\end{array}$ \\
\hline Helen & Práticas Vocais Coletivas IV & $\begin{array}{l}\text { Cantar coletivamente e cantar } \\
\text { individualmente }\end{array}$ \\
\hline Fabiola & $\begin{array}{c}\text { Prática de Ensino de Língua Portuguesa e } \\
\text { Literatura }\end{array}$ & Variam conforme o componente curricular \\
\hline Denise & Multiletramentos & Produção de texto, seminário \\
\hline Sueli & Laboratório para o Ensino Fundamental & $\begin{array}{c}\text { Videoaulas, oficinas, experimentações com } \\
\text { objetos manipuláveis, questões abertas, } \\
\text { relatório (portfólio digital) }\end{array}$ \\
\hline Paulo & Laboratório de Física III & $\begin{array}{c}\text { Prova (lista de exercícios, videoaula e o } \\
\text { trabalho prático-teórico direcionados à } \\
\text { recuperação) }\end{array}$ \\
\hline Lúcio & Laboratório de Química Geral & $\begin{array}{l}\text { Caderno de laboratório, relatórios, prova } \\
\text { teórico-prática, participação na aula } \\
\text { prática, a presença em aula, uso dos } \\
\text { equipamentos de proteção individual }\end{array}$ \\
\hline Gustavo & Física Geral III & $\begin{array}{c}\text { Prova objetiva e problemas (início do } \\
\text { curso), seminários, palestras (final do } \\
\text { curso) }\end{array}$ \\
\hline Gisele & Economia Industrial & Prova, lista e trabalhos em grupo \\
\hline
\end{tabular}

Fonte: Elaboração das autoras (2020).

Assim, salienta-se que, para além da variedade de instrumentos, é fundamental que se tenha clareza dos objetivos que se deseja alcançar através deles, buscando fazer o melhor uso possível de tais fontes. Além disso, em complemento aos registros desenvolvidos para os alunos, as anotações do professor são importante elemento para observar os processos individuais e coletivos sob diferentes perspectivas (HOFFMANN, 2001, p. 180).

Percebeu-se, por meio das entrevistas, o caráter de flexibilidade dos instrumentos descritos nos planos de ensino e do próprio plano que formaliza tais instrumentos, uma vez que, entre os professores, apenas um disse não modificar os instrumentos de avaliação em função dos semestres e do perfil das turmas, e outro disse utilizar geralmente os mesmos. No que tange a esse aspecto, entretanto, foi possível observar algumas contradições e possíveis incertezas dos entrevistados.

Considerando as particularidades de cada turma, assim como as características individuais de aprendizagem, considera-se positivo que o planejamento e possíveis modificações dos instrumentos de avaliação sejam feitos com base no diagnóstico da turma. Esse seria um caminho favorável para uma avaliação que permita observar aspectos próprios de cada estudante. A esse respeito, o planejamento dos instrumentos de avaliação não deve ser realizado desarticulado das vivências do grupo de alunos (HOFFMANN, 2001), uma vez que a “[...] avaliação atravessa o ato de planejar 
e executar" (LUCKESI, 2011, p. 137), direcionando alternativas para melhorias do processo. Dessa forma, em relação à modificação dos instrumentos de acordo com o perfil das turmas, destaca-se a fala de Sueli:

Sim, eu não consigo fazer igual. E, assim, eu tenho loucura... porque eu acabo me matando... porque eu não consigo fazer igual em duas turmas, eu até tento aproveitar alguma coisa.

No excerto acima, Sueli revela a complexidade do processo avaliativo também pela perspectiva docente, em contraposição ao que normalmente encontramos na literatura, que destaca as problemáticas da avaliação pelo viés do estudante. Para ela, avaliar e modificar constantemente se torna uma "loucura", a qual gera sobrecarga de trabalho ("acabo me matando"). A docente também ressaltou que as atividades poderiam ser modificadas, citando exemplos de turmas com alunos mais velhos, ou turmas numerosas.

Fabiola, pautando-se nos prazos institucionais exigidos para a entrega dos planos de ensino, não esclarece se modifica ou não os instrumentos de avaliação, argumentando que:

É que é complicado tu avaliar perfil da turma porque a gente tem que entregar já um plano de ensino, né, por mais que eu vá avaliar os alunos nas primeiras aulas para produzir o meu, eu tenho que entregar o meu plano na segunda semana, na segunda semana eu não conheço ainda, eu não sei qual é o perfil da turma.

Por outro lado, ao ser questionada a respeito dos instrumentos utilizados, a professora afirmou que eles são variáveis conforme o componente curricular. A queixa da professora esbarra em uma limitação criada pela burocracia institucional, que define que o sistema acadêmico exige o prazo limite de duas semanas após o início das aulas para modificação do plano de ensino, para que as aulas comecem a ser lançadas nos diários de classe on-line. Tal limitação influencia a tomada de decisão em relação à possibilidade de acompanhamento mais aprofundado das turmas, para então definir, conjuntamente ou não com os alunos, os instrumentos e critérios avaliativos mais adequados.

Gustavo, ao afirmar que os instrumentos são pensados de acordo com os avanços em relação ao conteúdo trabalhado, ressalta:

É... na verdade, o que a gente muda de acordo com o perfil da turma é o conteúdo trabalhado, o quanto profundo a gente tá que:: vai nos conteúdos, então se a gente tem uma turma em que os alunos têm uma resposta boa ao a:: aulas, vamos dizer assim... então a gente acaba aprofundando, vendo mais detalhe. É lógico que isso acaba refletindo 
na avaliação, né? A gente faz uma avaliação proporcional ao conteúdo que a gente consegue avançar.

Por um lado, o docente demonstra flexibilidade quanto à progressão curricular em relação ao processo avaliativo, ao reconhecer que uma turma que apresenta uma "resposta boa" é exposta a um maior detalhamento do conteúdo. Entretanto, frente a uma situação oposta a esse quadro, é possível pensar em um possível prejuízo para as turmas que apresentam ritmo de aprendizado menos expressivo, pois os conteúdos trabalhados não chegariam a atingir o mesmo grau de complexidade previsto pelo componente. Ao responder que modifica os instrumentos em relação à turma, Helen argumenta que:

\section{[...] ahn:: sim, já fiz isso também de:: em relação a turma modificar, eu acho que mais do que os instrumentos, eu modifico o meu olhar sobre o instrumento. Pode ser o mesmo, mas talvez o meu nível não de exi- gência, mas o nível de:: cobrança, a depender... né... da turma ou de como a turma se organiza pra estudo, pra que as práticas possam ser um pouquinho diferentes.}

A professora evita mencionar que altere o "nível de exigência”, retificando a sua fala em termos de "cobrança", em uma associação à metáfora da avaliação como uma prestação de contas, na qual, para quem "dá mais" é possível "cobrar mais", na mesma lógica apresentada anteriormente pelo professor Gustavo. Há, entretanto, na fala da docente, um movimento interessante, quando menciona a ideia do "olhar". No mesmo sentido, Hoffmann (2001, p. 180) argumenta que, “[...] muitas vezes, não se trata de fazer tarefas diferentes, mas de interpretar de forma diferente as tarefas e os registros que se fazem”. Também Hadji (2001) contribui ao discutir sobre a busca dos elementos observáveis em avaliação, afirmando que esse processo é pautado pela produção da informação, cujos indicadores nunca são dados imediatos, mas que devem ser trabalhados à luz de critérios previamente definidos. Ao pensar na perspectiva de uma avaliação orientada por critérios, parece problemática a diminuição de conteúdos para atender ao perfil de uma turma de menor desempenho e não a criação de estratégias que busquem modificar tal perfil.

Em relação às vantagens e desvantagens observadas ao adotar os instrumentos citados, com base nas respostas dos docentes, notou-se a necessidade de categorizá-las de forma geral, conforme o Quadro 6. 
QUADRO 6 - Vantagens e desvantagens dos instrumentos citados na ótica docente

\begin{tabular}{|c|c|c|}
\hline INSTRUMENTO & VANTAGENS & DESVANTAGENS \\
\hline Trabalho teórico-prático & Motivação/união teoria e prática & Trabalho interpessoal \\
\hline Prova & $\begin{array}{c}\text { Flexibilização dos instrumentos/ } \\
\text { mais cômodo para corrigir/registro e } \\
\text { documentação }\end{array}$ & $\begin{array}{c}\text { Alunos pouco preparados, não saber o que } \\
\text { mudar/trabalho e tempo para correção/ } \\
\text { cola/não ter certeza se o aluno decorou } \\
\text { a resposta/dificuldades de expressão do } \\
\text { aluno }\end{array}$ \\
\hline Seminário & $\begin{array}{l}\text { Possibilidade de adaptação às } \\
\text { necessidades dos alunos }\end{array}$ & Falta de objetividade \\
\hline Geral & $\begin{array}{l}\text { Diversidade de instrumentos/ } \\
\text { desenvolvimento como docente }\end{array}$ & $\begin{array}{c}\text { Instrumentos que só permitem } \\
\text { acompanhar o processo, mas não pontos } \\
\text { isolados/mais trabalho de correção/difícil } \\
\text { acompanhar o desenvolvimento de todos/ } \\
\text { difícil correção semanal }\end{array}$ \\
\hline
\end{tabular}

Fonte: Elaboração das autoras (2020).

No Quadro 6, destacam-se os principais aspectos dos instrumentos mais citados nas entrevistas, elencados pelos docentes. Tais características refletem o papel da prova como instrumento de documentação e registro e pela comodidade para corrigi-la. Em contrapartida, sobre os demais instrumentos, de forma geral, os professores buscam atrelá-los a suas preocupações em relação ao desenvolvimento dos alunos, bem como ao seu próprio desempenho como docentes.

Dessa maneira, considera-se a prova como um instrumento que, para além do registro e facilidades de correção, permite a análise dos processos individuais e coletivos, desde que seja elaborada com tal finalidade, pois “[...] é necessária a elaboração de instrumentos de avaliação confiáveis para um acompanhamento também confiável" (HOFFMANN, 2001, p. 179). Os dados ainda corroboram os resultados encontrados por Silva e Mendes (2017, p. 285-286), ao ressaltarem:

\begin{abstract}
A predominância da utilização da prova, aliada ou não a outros procedimentos avaliativos, em todos os cursos participantes dessa etapa da investigação. Além disso, ao falarmos sobre a distribuição das notas, pudemos observar também que a maioria das propostas avaliativas que incluem a prova e outros procedimentos, enfatiza a prova, atribuindo- Ihe a maior parcela da nota. É interessante destacar que, muitas vezes, é construído um clima de tensão em torno da aplicação da prova, o que pode desestabilizar emocionalmente o(a) estudante e impactar de modo negativo nos seus resultados.
\end{abstract}

A partir disso, podemos nos remeter a Gatti (2003, p. 101), ao ressaltar que:

A atribuição de notas ou gradações a um grupo de alunos é al go bastante pessoal entre os professores. Mesmo quando recebe instruções estritas quanto a como fazê-lo, introduzem em algum ponto variações que Ihes permitem dar seu cunho pessoal à avaliação. Há sempre um certo grau 
de subjetividade que atua no processo e isto nem sempre é objeto de reflexão por parte do professor.

Perrenoud (1999), ao refletir a respeito do papel da memorização para alcançar a excelência, constata que, ao ser utilizada em grande escala, é uma prática que precisa ser reconsiderada, em especial quando se trata do ensino superior, que requer o desenvolvimento de habilidades cognitivas com maior grau de complexidade, alinhadas ao desempenho profissional futuro.

Nesse contexto, torna-se necessário (re)pensar a distribuição dos pesos entre os instrumentos utilizados, bem como ampliar, em alguns casos, a sua variedade, observando as características das turmas. Entre as alternativas apontadas estão o seminário e os trabalhos teórico-práticos, os quais permitem perceber e instigar a proatividade, a capacidade de relação interpessoal e a resolução conjunta de tarefas e problemas.

Para Carbonesi (2014), o seminário permite ao aluno a construção de posicionamentos que considerem as contribuições para o trabalho do outro, assim como fomentar a pesquisa e o estudo orientado. No mesmo sentido, Hadji (2001, p. 86, grifos no original) observa que as tarefas não devem obedecer tão somente "[...] a uma exigência de pertinência, mas também de significância”, sendo necessário definir os critérios e objetivos almejados pela utilização dos seminários. Os trabalhos teórico-práticos, por sua vez, permitem observar capacidades de correlação entre os dois aspectos fundamentais da formação e, quando pautados em propostas bem planejadas, constituem-se instrumentos de avaliação fundamentais para perceber dificuldades específicas.

Além disso, ao serem questionados a respeito das desvantagens dos instrumentos utilizados, os professores demonstraram insegurança em alguns aspectos, entre eles as dificuldades de correção, de acompanhar o desenvolvimento de todos, de realizar tarefas avaliativas com mais frequência, além da falta de preparação e desinteresse dos alunos e da falta de objetividade na definição dos critérios de avaliação.

Mesmo com essas inseguranças e com as desvantagens citadas, os professores relataram estar satisfeitos com os instrumentos utilizados, destacando o aprimoramento constante, conforme a fala de Denise:

Eu não tenho uma satisfação plena, mas, grosso modo, dá pra dizer que sim, eu tenho uma satisfação no sentido de que eu sou coerente, acho que é por aí, né? Eu sou coerente com o que eu entendo que é importante no processo de avaliação da aprendizagem.

Sueli, ao relatar sua satisfação com os instrumentos que utiliza, afirmou:

Ah, eu me considero, porque, cada vez que eu estou insatisfeita, eu modifico. 
Para Helen, que assume a conquista dessa satisfação com o tempo de docência, a busca é constante e requer aperfeiçoamento dos instrumentos de avaliação e, sobretudo, do olhar docente sobre o que observa nos instrumentos. Com base nas falas dos professores entrevistados, reflete-se que "[...] sem uma formação específica em avaliação, reproduzem os professores a forma que foram avaliados enquanto estudantes" (HOFFMANN, 2001, p. 211). Por sua vez, Ranjard (1984) alerta para as dificuldades que os professores têm para sair de sua zona de segurança cotidiana em relação às provas.

Por fim, alerta-se para a importância de refletir, de fato, sobre as práticas de avaliação. Os instrumentos utilizados e a complexidade dos elementos vinculados ao processo avaliativo são também um movimento necessário por parte da política de formação continuada dos docentes universitários, muitas vezes tratado de forma secundária perante a amplitude de tarefas que compreende a atuação do professor universitário, com demandas vinculadas não só ao ensino, mas também à extensão, à pesquisa e à gestão, como se recomenda, especialmente no caso das instituições públicas federais. O caminho de mudanças vem sendo construído a cada passo, sendo necessária a compreensão dos atores envolvidos sobre o que está em jogo durante o processo avaliativo e qual a sua real importância ao longo da formação profissional universitária.

\section{CONSIDERAÇÕES FINAIS}

Neste trabalho, buscou-se diagnosticar as formas de avaliação da aprendizagem, os instrumentos e questões relacionadas e identificar possíveis indícios de inovações avaliativas emergentes em um campus de uma universidade pública multicampi localizada no Sul do Brasil no âmbito de cursos de engenharias e de licenciaturas na perspectiva de docentes atuantes na instituição.

A análise dos planos de ensino dos cursos de engenharias e licenciaturas mostrou que ainda são poucos os componentes curriculares que apresentam variedade de propostas e instrumentos de avaliação, sendo que boa parcela dos componentes que fizeram parte da análise apresentava significativa carga horária prática. Segundo os professores, esse elemento requer formas variadas de avaliação, uma vez que fatores próprios da prática de laboratório devem ser considerados para o processo de aprendizagem. Como contraponto, vale a pena instigar a reflexão a respeito de quais crenças vêm sendo mobilizadas para incidir sobre o caso de componentes de natureza apenas teórica, já que a mesma diversificação de instrumentos utilizada nas disciplinas teórico-práticas tem sido menos viabilizada nas disciplinas teóricas no campus universitário analisado nesta pesquisa.

Percebe-se também que tanto nos planos quanto nas entrevistas a prova é o instrumento mais utilizado entre os docentes e, em geral, aquele que tem maior peso 
entre as tarefas adotadas. Nesse âmbito, acredita-se que, quanto mais variados os registros, melhores serão as percepções do professor em relação ao desenvolvimento dos alunos, possibilitando ainda o equilíbrio entre os pesos dos instrumentos. Nesse caso, nenhum deles é completamente decisivo, mas sim complementares ao conjunto de tarefas desempenhadas.

Os professores argumentam que a utilização dos instrumentos de avaliação varia de acordo com o curso, o componente, os avanços em relação ao conteúdo e a turma. Entre os entraves para a adaptação da avaliação, conforme o perfil da turma, aparecem os prazos institucionais para a entrega dos planos de ensino, o que impossibilitaria o diagnóstico da turma para o planejamento dos instrumentos de avaliação durante o semestre.

Além disso, percebe-se que atividades de recuperação nem sempre são realizadas de forma paralela, sendo que alguns docentes as realizam apenas ao final do componente para os alunos que não alcançaram a média mínima (no caso da universidade referida, nota 6 para os cursos de graduação) e como forma de substituição da menor nota. Entre os docentes que realizam a recuperação paralela, em geral são descritas orientações individuais ou tarefas pequenas.

Os professores entrevistados destacaram que as vantagens de utilizar os instrumentos descritos eram a comodidade para correção, no caso da prova, a motivação e possibilidade de adaptação conforme as necessidades dos alunos, com os trabalhos teórico-práticos, seminários e o desenvolvimento docente, de maneira geral. Dessa forma, ressalta-se que as mudanças em avaliação são necessárias e possíveis de serem efetuadas, sendo que os resultados mostram um caminho em construção, que atravessa o campo das comodidades docentes e inicia um percurso de novas percepções.

Por fim, enfatizamos que, quanto mais conjuntamente forem estabelecidos esses caminhos (com o compartilhamento de boas práticas em rodas de conversa e grupos de estudo sobre a temática da avaliação), mais qualificado será o processo avaliativo e mais agentes poderão se mobilizar para alterarem as práticas cristalizadas, promovendo, de fato, inovações avaliativas que considerem os contextos locais e embasadas na literatura da área.

\section{REFERÊNCIAS}

ACEVEDO, F. Análisis de la persistencia estudiantil en el primer año de la educación superior en un contexto socio-académico desfavorable: el caso de Rivera, Uruguay. 2018. Tese (Doutorado em Sociedad del Conocimiento y Acción en los ámbitos de la Educación, la Comunicación, los Derechos y las Tecnologías) - Universidad Internacional de la Rioja, La Rioja, 2018. 
Docente, Confresa, MT, v. 5, n. 3, p. 1568-1592, dez. 2020. DOI: https://doi.org/10.23926/RPD.25262149.2020.v5.n3.p1568-1592.id886

BLASS, L.; IRALA, Valesca. Desenho avaliativo por rubricas em disciplina multicurso: análise de uma implementação piloto. HOLOS, v. 7, e9518, dez. 2020. Disponível em: http://www2.ifrn.edu. br/ojs/index.php/HOLOS/article/view/9518. Acesso em: 11 fev. 2021. DOI: https://doi.org/10.15628/ holos.2020.9518

BOGDAN, R.; BIKLEN, S. Investigação qualitativa em educação: uma introdução à teoria e aos métodos. Porto: Porto, 1994.

BONDÍA, J. L. Notas sobre a experiência e o saber de experiência. Revista Brasileira de Educação, Rio de Janeiro, n. 19, p. 20-28, jan./abr. 2002.

BONI, V.; QUARESMA, S. J. Aprendendo a entrevistar: como fazer entrevistas em ciências sociais. Em Tese, Florianópolis, v. 2, n. 1, p. 68-80, jan./jul. 2005.

BORTONI-RICARDO, S. M. O professor pesquisador: introdução à pesquisa qualitativa. São Paulo: Parábola, 2008.

BRASIL. Lei n. 9.394, de 20 de dezembro de 1996. Estabelece as diretrizes e bases da educação nacional. Brasília, DF, 1996. Disponível em: http://www.planalto.gov.br/ccivil_03/leis/19394.htm. Acesso em: 27 maio 2021.

BRASIL. Ministério da Educação. Parecer CNE/CP n. 28, de 2 de outubro de 2001. Dá nova redação ao Parecer CNE/CP 21/2001, que estabelece a duração e a carga horária dos cursos de Formação de Professores da Educação Básica, em nível superior. Brasília, DF: Ministério da Educação, 2001.

BRITTO JÚNIOR, A. F.; FERES JÚNIOR, N. A utilização da técnica da entrevista em trabalhos científicos. Evidência, Araxá, MG, v. 7, n. 7, p. 237-250, 2011.

CAMARGO, S.; BORIN, J.; AMARAL, E.; FERREIRA, A. P. Identificação dos padrões de evasão de cursos de engenharia a partir de dados de desempenho acadêmico. In: CONGRESSO BRASILEIRO DE EDUCAÇÃO EM ENGENHARIA, 42., 2014, Juiz de Fora, MG. Anais [...]. Juiz de Fora: Abenge, 2014.

CARBONESI, M. A. R. M. O uso do seminário como procedimento avaliativo no ensino superior privado. In: CONGRESSO IBERO-AMERICANO DE POLÍTICA E ADMINISTRAÇÃO DA EDUCAÇÃO, 4., 2014, Porto (Portugal). Anais [...]. Porto: Anpae, 2014. Disponível em: http://anpae.org.br/ IBERO_AMERICANO_IV/GT2/GT2_Comunicacao/MariaAnastaciaRibeiroMaiaCarbonesi_GT2_ integral.pdf. Acesso em: 30 jan. 2020.

CARLESS, D. Learning-oriented assessment: principles, practice and a project. In: MEYER, L. H.; DAVISON, S.; ANDERSON, H.; JOHNSHON, P. M.; REES, M. (ed.). Tertiary assessment \& higher education student outcomes: policy, practice \& research. Wellington, Nova Zelândia: Ako Aotearoa, 2009. p. 79-90. Disponível em: https://www.researchgate.net/publication/295568484_Learningoriented_assessment_Principles_and_practice. Acesso em: 14 jun. 2020.

CECHINEL, A.; FONTANA, S. A. P.; GIUSTINA, K. P. D.; PEREIRA, A. S.; PRADO, S. S. do. Estudo/ análise documental: uma revisão teórica e metodológica. Criar Educação, Criciúma, SC, v. 5, n. 1, jan./jun. 2016. 
CHAVES, S. M. Avaliação da aprendizagem no ensino superior: realidade, complexidade e possibilidade. In: REUNIÃO ANUAL DA ASSOCIAÇÃO NACIONAL DE PÓS-GRADUAÇÃO E PESQUISA EM EDUCAÇÃO, 27., 2004, Caxambu. Anais [...]. Caxambu, MG: Anped, 2004. Disponível em: http://www.anped.org.br/sites/default/files/t0412.pdf. Acesso em: 30 jan. 2020.

DEPRESBITERIS, L.; TAVARES, M. R. Diversificar é preciso...: instrumentos e técnicas de avaliação de aprendizagem. São Paulo: Ed. Senac, 2017.

DOCHY, F.; SEGERS, M.; DIERICK, S. Nuevas vías de aprendizaje y enseñanza y sus consecuencias: una nueva era de evaluación. Boletín de la Red Estatal de Docencia Universitaria, v. 2, n. 2, p. 13-29, 2002.

DORNELLES, C. A reforma curricular e o debate sobre língua e ensino no curso de Letras. In: SIGNORINI, I.; FIAD, R. (org.). Ensino de línguas: das reformas, das inquietações, dos desafios. Belo Horizonte: Editora da UFMG, 2012. p. 122-143.

FLICK, U. Introdução à pesquisa qualitativa: um guia para iniciantes. Porto Alegre: Penso, 2013.

FLUCK, A.; HILLIER, M. Innovative assessment with eExams. In: AUSTRALIAN COUNCIL FOR COMPUTERS IN EDUCATION CONFERENCE, 2016, Brisbaine, Queensland, Austrália. Anais [...]. Brisbaine: AARNet, 2016. Disponível em: https://www.researchgate.net/publication/314352356_ Innovative_assessment_with_eExams. Acesso em: 31 jan. 2020.

FRAILE, J.; GIL-IZQUIERDO, M.; ZAMORANO-SANDE, D.; SÁNCHEZ-IGLESIAS, I. Autorregulación del aprendizaje y procesos de evaluación formativa en los trabajos en grupo. RELIEVE, v. 1, n. 26, p. 1-15, 2020.

GATTI, B. A. O professor e a avaliação em sala de aula. Estudos em Avaliação Educacional, São Paulo, n. 27, p. 97-114, jan./jun. 2003.

GONÇALVES, A. L.; LARCHERT, J. M. Avaliação da aprendizagem: pedagogia. Ilhéus, BA: Editus, 2011. HADJI, C. Avaliação desmistificada. Porto Alegre: Artmed, 2001.

HOFFMANN, J. Avaliar para promover: as setas do caminho. 15. ed. Porto Alegre: Mediação, 2001.

LOCK, J.; KIM, B.; KOH, K.; WILCOX, G. Navigating the tensions of innovative assessment and pedagogy in higher education. The Canadian Journal for the Scholarship of Teaching and Learning, v. 9, n. 1, p. 1-18, Apr. 2018.

LUCKESI, C. C. Avaliação da aprendizagem escolar: estudos e preposições. 19. ed. São Paulo: Cortez, 2011.

MASSONI, N.; MOREIRA, M. Pesquisa qualitativa em educação em Ciências. São Paulo: Livraria da Física, 2016.

MISSIO, D.; CARVALHO, N.; SOUZA, T.; LEIVAS, F.; BRUM, D.; MELLO, E. Retenção e evasão no curso de Medicina Veterinária da Unipampa: algumas reflexões. Educação Brasileira, Brasília, DF, v. 38, n. 76/77, p. 178-204, dez. 2016.

NORAINIIDRIS; KRISHNAN, S.; ROSLINDAITHNIN; FADZILDAUD, M.; MUSTAPHA, Z. Innovating higher education: redesigning assessment. International Journal of Management and Applied Science, v. 1, n. 8, p. 96-98, Sept. 2015. 
PERRENOUD, P. Avaliação: da excelência à regulação das aprendizagens - entre duas lógicas. Porto Alegre: Artes Médicas, 1999.

RANJARD P. Les enseignants persécutés. Paris: Robert Jauze, 1984.

SILVA, N. L.; MENDES, O. M. Avaliação formativa no ensino superior: avanços e contradições. Avaliação: Revista da Avaliação da Educação Superior, Campinas; Sorocaba, SP, v. 22, n. 1, p. 271-297, jan./abr. 2017.

SILVEIRA, D. T.; CÓRDOVA, F. P. A pesquisa científica. In: GERHARDT, T. E.; SILVEIRA, D. T. (org.). Métodos de pesquisa. Porto Alegre: Editora da UFRGS, 2009.

TINTO, V. Completing college: rethinking institutional action. Chicago: The University of Chicago Press, 2012.

TOBÓN, S. Evaluación socioformativa: estrategias e instrumentos. Mount Dora, EUA: Kresearch, 2017.

VIANNA, H. M. Avaliação educacional: uma perspectiva histórica. Estudos em Avaliação Educacional, São Paulo, v. 25, n. 60 (n. especial), p. 14-35, dez. 2014a.

VIANNA, H. M. Avaliando a avaliação: da prática à pesquisa. Estudos em Avaliação Educacional, São Paulo, v. 25, n. 60 (n. especial), p. 170-177, dez. 2014b.

VON DAVIER, A. A.; ZHU, M.; KYLLONEN, P. C. (org.). Innovative assessment of collaboration (Methodology of education measurement and assessment). Cham, Suíça: Springer, 2017.

ZIMMERMANN, C. C.; BASTOS, L.; BUTTCHEVITZ, A.; RIBAS, C.; PINTOS, F.; GERALDI, M.; PEDRO, R. Análise estatística dos fenômenos de reprovação e evasão no curso de graduação em Engenharia Civil da Universidade Federal de Santa Catarina. In: CONGRESSO BRASILEIRO DE EDUCAÇÃO EM ENGENHARIA, 39., 2011, Blumenau. Anais [...]. Blumenau: Abenge, 2011.

\section{COMO CITAR ESTE ARTIGO:}

IRALA, Valesca Brasil; MENA, Liziane Padilha. Avaliação discente na percepção de docentes da educação superior. Estudos em Avaliação Educacional, São Paulo, v. 32, e07107, 2021. DOI: https://doi.org/10.18222/eae.v32.7107

Recebido em: 31 JANEIRO 2020

Aprovado para publicação em: 12 ABRIL 2021

Este é um artigo de acesso aberto distribuído nos termos da licença Creative Commons do tipo BY-NC. 